\title{
UM ESTUDO DIACRÔNICO DA CONCEPÇÃO DE ESCRITA E PRODUÇÃO TEXTUAL NA REVISTA NOVA ESCOLA
}

\section{A DIACHRONIC STUDY OF THE CONCEPT OF WRITING AND TEXTUAL PRODUCTION IN NOVA ESCOLA MAGAZINE}

Submetido em: 08-12-2012

Publicado em: 23-02- 2013

Ana Paula Flores

Mestranda do Programa de Pós-Graduação em Linguística da Universidade Federal de Santa Catarina (UFSC). Formada em 2009 no curso de Jornalismo pela mesma instituição. anapflores86@gmail.com

Joice Eloi Guimarães ${ }^{1}$

\begin{abstract}
Resumo: O objetivo deste trabalho é analisar, por meio de uma seleção cronológica de textos da revista Nova Escola, as mudanças referentes às concepções e práticas de escrita nesse veículo de comunicação impresso. Para tanto, executamos o mapeamento e a análise de matérias que se referem à produção escrita no período compreendido entre 1986 e 2010, contrapondo-as às instruções presentes nos documentos oficiais que regem as práticas pedagógicas de Língua Portuguesa (LP) no período analisado. Foram utilizados os seguintes critérios de análise: concepção de escrita; gêneros textuais mais frequentes; a que série as atividades relatadas se referem; metodologia explicitada e, por fim, o peso dado à correção gramatical. Em linhas gerais, os resultados da análise apontaram que houve, por parte da revista, um movimento de apropriação das práticas de linguagem discutidas em cada período. Percebemos que o veículo, ainda que não simultaneamente, acompanhou as mudanças demandadas pela prática da disciplina LP e, ao longo dos anos, sua visão de produção textual é claramente modificada: o foco sai da redação (anos 1980) para um intenso trabalho com os gêneros textuais (anos 2000).
\end{abstract}

Palavras-chave: Escrita. Produção de textos. Revista Nova Escola.

Abctract: In this article we have the intention of analyze, through a chronological selection of texts from the magazine Nova Escola, the changes related to the concepts and writing practices in this printed publication. To achieve this goal, we have selected and analyzed written texts production between 1986 and 2010, comparing to the instructions from the official documents that conduct the pedagogic practices of native language (Portuguese). We've used the following analysis criteria: conception of writing; frequently textual genres; which grade the described activities refer; explicitly methodology and, finally, the importance gave to the grammatical correction. The results of the analysis indicated that the magazine made a movement of appropriation of language practices discussed in each period. We realize that the publication, even thought in a non-simultaneous way, keep up with the changes demanded by the native language practices and, along the years, its sight of textual production

\footnotetext{
${ }^{1}$ Mestrandas da Universidade Federal de Santa Catarina (UFSC). Contatos: anapflores86@gmail.com, joiceeg@hotmail.com
}

Work. pap. linguíst., 13(2): 58-82, Florianópolis, jul.set,2012 
is clearly changed: the focus moves from the simple composing towards an intense work with textual genres.

Keywords: Writing. Textual production. Nova Escola magazine.

\section{INTRODUÇÃO}

Em uma perspectiva histórica, é possível perceber as mudanças ocorridas em relação à prática de produção de textos na esfera escolar. Inicialmente entendida como um agrupamento de palavras e frases, ensinada a partir da correta utilização das tradicionais regras da gramática normativa e da ortografia, a escrita é concebida atualmente "como um processo de interlocução entre leitor-texto-autor que se concretiza via gêneros textuais em um contexto sócio-historicamente situado" (MARCUSCHI, 2010, p. 79). As práticas sociais, dentro e fora da escola, o estudo de novas concepções de linguagem e as orientações presentes nos documentos norteadores das práticas educativas são fatores que interferem nessas mudanças.

Por meio da história da disciplina Português como componente escolar, percebemos que, no início, as práticas com a escrita tinham espaço insignificante. É a partir da década de 1980 que se volta um olhar mais atento para essa prática, para seu histórico ineficiente - que apresentava como resultado, na maioria dos casos, alunos que saíam da escola sem terem condições de produzir um bom texto - e para as mudanças necessárias à reversão desse quadro. Para tanto, foram de fundamental importância nesse período as contribuições das ciências linguísticas, introduzidas nos currículos de formação de professores a partir dos anos 1960, com reflexo nas práticas escolares nos anos 1980 (SOARES, 2002).

Nesse contexto, em que se realizaram discussões no meio acadêmico com vistas à melhoria da prática docente, é criada, em 1986, a Revista Nova Escola. Dirigida à comunidade escolar, a revista traz reportagens com o objetivo de levar ao professor contribuições para sua prática em sala de aula.

Tomando como referência esse contexto, o objetivo deste trabalho é analisar, a partir de uma seleção de textos da revista, as mudanças referentes às concepções e práticas de desenvolvimento da escrita no período compreendido entre as décadas de 1980 e 2000 . Para tanto, pretende-se executar o mapeamento e a análise de matérias que contemplem o foco da pesquisa, contrapondo-as às concepções de escrita presentes nos documentos norteadores do ensino no mesmo período.

Work. pap. linguíst., 13(2): 58-82, Florianópolis, jul.set,2012 


\section{REVISÃO DE LITERATURA}

Diante da proposta desta pesquisa, inicialmente faremos uma contextualização das concepções e práticas de escrita produzidas no ambiente escolar com enfoque nas décadas sob análise neste artigo - 1980, 1990 e 2000. Apresentaremos também as orientações em relação à prática da escrita na escola presentes nos documentos oficiais que norteiam o ensino nesse período, a Lei 5692 de Diretrizes e Bases da Educação Nacional, de 1971 (LDB 1971); a Lei 9394 de Diretrizes e Bases da Educação Nacional, de 1996 (LDB 1996), que revisitou a lei anterior propondo mudanças como na nomenclatura utilizada para se referir as disciplinas curriculares referentes aos processos de ensino-aprendizagem de língua materna na escola; e os Parâmetros Curriculares Nacionais do Ensino Fundamental I e II (BRASIL, 1997; 1998), que regem o ensino desde sua publicação até os dias atuais.

Situaremos ainda a Revista Nova Escola histórica e socialmente na esfera jornalística, contextualizando também aspectos mais específicos, como seu público, objetivos e finalidades enquanto veículo de comunicação.

\subsection{A concepção de escrita na trajetória da disciplina Português}

A história da disciplina Português no Brasil é recente, tendo em vista o modelo colonial aqui estabelecido e a grande influência exercida pela Metrópole e demais padrões europeus mesmo após a Independência, em $1822^{2}$. De acordo com Soares “a disciplina português manteve, de certa forma, até os anos 40 do século XX, a tradição da gramática, da retórica e da poética" (SOARES, 2002, p. 164), porque o público a quem a escola servia continuou o mesmo, a elite da sociedade brasileira. Segundo a autora, tal contexto permitiu que, na disciplina Português, persistisse o estudo da gramática da retórica e da poética, esses

\footnotetext{
${ }^{2}$ Tal influência fez com que perdurasse no ensino a forte tradição em torno do Latim, disseminando a ideia do português como língua "menor". De acordo com Razzini (2000), é somente a partir de 1870 que o ensino de português na escola ganha espaço maior, devido a sua inserção nos Exames Preparatórios, que habilitavam para o ingresso no ensino superior. Durante muito tempo o ensino secundário no Brasil subordinou-se a eles, guiando seu currículo pelos padrões impostos pelos exames. Por meio do trabalho desenvolvido por Razzini (2000) é possível perceber que as aulas de latim e português alternaram, durante o final do século XIX e início do século XX, períodos de importância no contexto escolar brasileiro. A longa hegemonia da tradição latina na escola brasileira decai a partir das Diretrizes e Bases da Educação Nacional, por meio da lei 4.024 de 20 de dezembro de 1961, que tornava optativo o estudo do latim, desaparecendo completamente do currículo escolar com a Lei de Diretrizes e Bases da Educação Nacional 5.692 de 1971, que o mantinha apenas nos cursos superiores de Letras.
} 
dois últimos voltados para o 'escrever bem', substituindo, por exigências do contexto social, o 'falar bem', até então priorizado nesses estudos. Essa tradição justifica-se porque, durante muito tempo, na escola, acreditou-se que, para se escrever bem, era necessário o domínio das regras gramaticais, ignorando nesse contexto a relação da língua com a vida.

Nas décadas de 1950 e 1960, devido ao movimento de democratização da escola brasileira, esse quadro começa a ser questionado, pelo fato de os alunos que passaram a frequentar as salas de aula trazerem consigo variedades da língua e leituras de mundo que já não podiam mais ser ignoradas, influenciando o modo como o professor lidava com essa diversidade.

O estabelecimento do Regime Militar, em 1964, e a consequente imposição de decretos governamentais voltados para a educação, agregam-se a esse processo de questionamentos que teve início com as propostas de democratização da escola anos antes. A LDB de 1971 decretou modificações abruptas em todas as disciplinas curriculares. Em relação ao ensino de língua materna, houve mudanças na nomenclatura - Comunicação e Expressão nas séries iniciais do $1^{\circ}$ grau, Comunicação em Lingua Portuguesa nas séries finais desse grau e Lingua portuguesa e Literatura Brasileira no $2^{\circ}$ grau- e na concepção de linguagem. Essa adquire agora objetivos pragmáticos e utilitários, visando ao desenvolvimento do uso da língua (SOARES, 2002). Essa concepção, porém, admitia a língua apenas como instrumento de quem se apropria no ato da comunicação, ou seja, como algo exterior aos sujeitos que a utilizam, considerando o ser falante apenas como o "emissor" de uma mensagem.

Na década de 1970, atenção maior passa a ser destinada às práticas da língua que materializam a comunicação, a oralidade e a escrita, como pode ser observado nos livros didáticos publicados nesse período. Neles, a importância da gramática é minimizada (SOARES, 2002), e passam a ser priorizados novos conteúdos que já não trazem somente os textos clássicos da literatura para as atividades relacionadas à leitura e à produção de texto na sala de aula, mas também textos que se aproximam dos usos da língua nas práticas sociais ${ }^{3}$, como história em quadrinhos e textos da esfera jornalística.

\footnotetext{
${ }^{3}$ Também a "cara" do livro didático passa a ser outra, pois aliado ao momento de desenvolvimento da indústria gráfica no Brasil, as novas ideias presentes nos livros vem acompanhadas de ilustrações coloridas que afastam esse modelo dos tradicionais livros didáticos utilizados até então.
} 
De acordo com Marcuschi, nesse ínterim, em que a sociedade passou a valorizar mais a capacidade do indivíduo de se comunicar de modo claro, em relação ao ensino da escrita, a escola vivenciava um conflito,

Ao mesmo tempo em que era chamada a estimular o aluno a expressar suas ideias de modo criativo, em atividades denominadas "redação", "redação livre" e "redação criativa", era pressionada a cercear a liberdade do aprendiz na emissão de posições sobre o status quo. (MARCUSCHI, 2010, p. 71)

Isso porque, segundo Soares (2002), a educação, durante o Governo Militar, sofreu mudanças não somente decorrentes das transformações sociais e culturais construídas historicamente, mas também por meio de intervenções ideológicas. O reflexo desse contexto no ambiente escolar pode ser observado no papel da escrita, que se mantinha condicionado às exigências externas à escola, sem, contudo, considerar esses contextos nas práticas de produção de texto desenvolvidas.

No final da década de 1970, como resultado das contribuições das ciências linguísticas nos cursos de formação de professores, começa-se a se pensar a linguagem em suas múltiplas realizações, incluída na constituição dos sujeitos como processo interativo. Por essa razão, surgem ideias que implicam o estudo dos processos envolvidos no ato de escrever. De acordo com Britto, as discussões desse período demonstram que "o aprendizado efetivo da escrita não decorre de um processo de treinamento, mas da inserção do sujeito no mundo, da relação que estabelece entre o que aprende e seu universo sócio histórico" (BRITTO, 1997, p. 100).

Nos anos de 1980, período em que começam a repercutir no ambiente escolar as fecundas discussões iniciadas na década anterior, a ineficiência das tradicionais práticas que vigoravam nesse espaço acentua-se.

Nesse período, avolumam-se as polêmicas entre os estudos da Linguística e a Gramática Tradicional. Para Pietri (2003), os setores letrados brasileiros acusavam a Linguística de ser permissiva, o que estaria ocasionando não apenas a deterioração do ensino, mas também a degradação do idioma nacional e, segundo Britto, nesse momento as críticas ao ensino da gramática tradicional evidenciam-se, "tanto do ponto de vista teórico (os erros e inadequações da teoria a ela subjacente) quanto do metodológico (sua forma de apresentação e a utilidade dos conceitos e valores oferecidos aos alunos)" (BRITTO, 1997, p. 102).

Ainda para Britto (1997), nesse período ações como a ampliação de linhas editoriais de bibliografia crítica, discussões entre especialistas, eventos de formação de professores acentuam o momento de mudança nos processos de ensino e aprendizagem de língua materna. 
A linguagem começa a ser vista como algo do qual o sujeito se apropria em uma perspectiva situada no tempo e espaço. Nessa perspectiva, a língua não pode mais ser considerada como um objeto pronto e acabado, já que o processo interlocutivo de atividade linguística faz com que ela esteja a cada momento em (re)construção, conforme Costa Val (1998),

Como um sistema que vai se constituindo e reconstituindo historicamente pela ação dos usuários, um sistema sensível ao contexto, plástico e flexível, que aceita e prevê variações, deslocamentos, inversões, ambiguidades, inovações [...] quando de sua utilização pelos falantes, nos processos de interação verbal. (apud MARCUSCHI, 2010, p. 73).

De acordo com Geraldi (1985), conceber a linguagem como lugar da interação humana implica uma postura educacional diferenciada, em que a linguagem é admitida como constituinte dos sujeitos que dela se utilizam. Nesse contexto, valorizam-se também as diversas formas de linguagem utilizadas nos processos de interação. Conforme Fortunato (2009), é nesse período que estudos da Linguística Textual passam a valorizar procedimentos de produção textual centrados na ativação dos saberes sociais acumulados pelos interlocutores, "Nessa abordagem, valorizam-se os conhecimentos e experiências dos interlocutores, que funcionam como expectativas de comunicação, tanto do ponto de vista do autor, ao traduzi-las em palavras, como do leitor, por ocasião da atividade de compreensão de textos" (FORTUNATO, 2009, p. 41).

Segundo Britto (1997), a ênfase atribuída nos processos de ensino aprendizagem de língua materna na escola ao ensino da gramática, valorizando, quase que exclusivamente, uma única variedade linguística, fez com que a escola deixasse de lado, nesses processos, o que o autor considera "fundamental no exercício da língua: o texto" (BRITTO, 1997, p. 102). Também os estudos de Geraldi apontam para a necessidade de se considerar a produção de textos como ponto de partida e de chegada de todo o processo de ensino/aprendizagem da língua. Porque, segundo o autor, é no texto que a língua - objeto de estudo -

[...] se revela em sua totalidade quer enquanto conjunto de formas e de seu reaparecimento, quer enquanto discurso que remete a uma relação intersubjetiva constituída no próprio processo de enunciação marcada pela temporalidade e suas dimensões (GERALDI, 1997, p. 135).

A partir dessa perspectiva, Geraldi ainda estabelece uma distinção esclarecedora entre produção de textos e redação. Ele atribui a primeira o caráter de produção de textos na escola; já à segunda atribui a característica de produção de textos para a escola. Ao avaliar superficialmente a concepção do ato de escrever para a escola, Geraldi considera que, a partir dos textos produzidos, a quantidade de produção escrita não significa que há muito texto: "há 
muita escrita e pouco texto (ou discurso)". Na visão dele, esse fato ocorre porque "se constroem nessas atividades, para cada um dos aspectos apontados acima, respostas diferentes daquelas que se constroem quando a fala (e o discurso) é para valer" (GERALDI, 1997, p. 137).

Para que o texto seja considerado como o aspecto central, o ponto de partida do processo de ensino/aprendizagem, Geraldi postula a necessidade de tomar a palavra do aluno como indicador "dos caminhos que deverão ser trilhados no aprofundamento quer da compreensão dos próprios fatos sobre os quais se fala quer dos modos (estratégias) pelos quais se fala”. (GERALDI, 1997, p. 165).

A concepção difundida na década de 1980 é fortalecida na década de 1990, com a propagação dos conceitos de Bakhtin. Apesar de o foco de atenção dos estudos desse autor não estarem voltados para as questões de ensino/aprendizagem, suas ideias têm impulsionado as discussões teóricas e o desenvolvimento pedagógico nas áreas relacionadas à linguagem com os gêneros do discurso como objeto de ensino, além das noções de interação verbal e dialogismo (RODRIGUES, 2005). De acordo com Bakhtin (2003), o emprego da língua efetua-se na forma de enunciados que refletem as condições específicas e as finalidades de cada campo da atividade humana. Segundo esse autor, cada enunciado particular é individual, mas cada campo de utilização da língua elabora seus tipos relativamente estáveis de enunciados, que são os gêneros do discurso.

A riqueza e a diversidade dos gêneros do discurso são infinitas porque são inesgotáveis as possibilidades da multiforme atividade humana e porque em cada campo dessa atividade é integral o repertório de gêneros do discurso, que cresce e se diferencia à medida que se desenvolve e se complexifica um determinado campo (BAKHTIN, 2003, p. 262).

Com a publicação dos Parâmetros Curriculares Nacionais (PCN) avolumaram-se as discussões acerca da inserção do conceito de gêneros na esfera escolar, pois esses documentos "preveem a adoção do texto como unidade e o gênero como objeto de ensino de Língua Portuguesa" (PETRONI, 2008, p. 12). Observamos que nos PCN a nomenclatura utilizada para se referir à disciplina responsável pelos processos de ensino e aprendizagem de língua materna no Ensino Fundamental é aquela presente na LDB 1996, “o ensino de Língua Portuguesa retoma o seu lugar, deixando de integrar a chamada "Comunicação e Expressão"” (SOUZA; SILVA, 1997, p. 50), documento em que é possível verificar a mudança em relação à lei anterior - LDB 5692/71. 
As discussões presentes nos PCN trazem à tona a urgência em pensar-se em propostas didáticas voltadas à aplicação do conceito de gênero nas práticas com a linguagem realizadas na escola. Os PCN, quando abordam o tratamento didático dos conteúdos, apresentam alguns encaminhamentos nesse sentido. Dentre as metodologias propostas, observa-se nos PCN destinados às séries finais do Ensino Fundamental (1998) a aproximação com o conceito de Sequência Didática (SD), formulado pelos professores e pesquisadores da equipe de Didática de Línguas da Faculdade de Psicologia e Ciências da Educação da Universidade de Genebra, Bernard Schneuwly, Joaquim Dolz e Michèle Noverraz, que são inclusive citados no documento.

A SD formulada pelos autores genebrinos constrói-se baseada na teoria dos gêneros discutida por Bakhtin (2003). Segundo seus idealizadores, uma SD "é um conjunto de atividades escolares organizadas, de maneira sistemática, em torno de um gênero textual oral ou escrito" (DOLZ; NOVERRAZ; SCHNEUWLY, 2004, p. 97). A produção escrita, nesse sentido, ocorre por meio de uma sequência de atividades desenvolvidas em torno de um gênero visando, ao final do processo, à produção do gênero proposto.

Nessa proposta os gêneros precisam ser compreendidos como produtos das relações histórico-sociais, e sua inserção nos processos de ensino e aprendizagem de línguas na escola faz parte da mudança em relação à concepção de linguagem que historicamente embasa esses processos, de uma concepção pautada na estrutura da língua para um entendimento da linguagem em sua complexidade, cujo estudo deve partir de sua realização concreta, ou seja, da utilização que se dá por meio da interação entre os falantes.

As propostas didáticas que operacionalizam o trabalho desenvolvido nas aulas de Língua Portuguesa chegam ao professor por diferentes meios, dentre esses destacamos a Revista Nova Escola, que tem o professor como interlocutor e visa a estabelecer com ele um diálogo que contribua no desenvolvimento de sua prática pedagógica.

\subsection{A Revista Nova Escola}

Conforme assinala Schelbauer (2007), ao longo das últimas décadas, historiadores da educação têm se debruçado sobre novas fontes de pesquisa, procurando encontrar registros sobre os caminhos percorridos pela história da educação. A autora destaca o papel que a imprensa ocupa no bojo dessas novas fontes, por proporcionar, "por meio de diversos olhares, a constituição do retrato de um tempo" (SCHELBAUER, 2007, p. 7). A pesquisa histórico- 
educacional tem se apropriado da chamada imprensa pedagógica ou educacional - formada por jornais e revistas - como objetos de estudo válidos para entender a participação da imprensa na dinâmica social, sobretudo sua influência na prática docente.

A Revista Nova Escola é uma publicação de periodicidade mensal ${ }^{4}$ de iniciativa da Fundação Victor Civita, nome do ex-presidente do Grupo Abril. Além das dez edições anuais da Nova Escola, a Fundação edita a revista Gestão Escolar, o site Nova Escola, o Prêmio Victor Civita - Educador Nota 10 e a Semana da Educação, ampliando, assim, suas ações como veículo de comunicação e informação.

No site da Fundação Victor Civita ${ }^{5}$, a publicação está apresentada da seguinte maneira: "Desde 1986, a revista Nova Escola contribui para a melhoria do trabalho dos professores dentro da sala de aula. Todo mês, ela antecipa, trata e dialoga com temas de interesse dos educadores, trazendo experiências reais e os conteúdos mais relevantes tanto de Educação Infantil como de Ensino Fundamental". Observamos que as publicações destinamse, sobretudo, à Educação Infantil e ao Ensino Fundamental. Apesar de verificarmos em algumas matérias apontamentos para atividades realizadas no Ensino Médio, esse não é o foco da revista. Por conta disso limitaremos nossa análise às matérias que trazem em seu conteúdo a produção escrita, destinadas às turmas do Ensino Fundamental ${ }^{6}$.

O site apresenta a Nova Escola como a maior revista especializada em Educação no Brasil. Informações do site ainda afirmam que, em números atualizados, a revista possui uma tiragem de 728.397 exemplares. O total de assinaturas é de 378.685 e 80.420 exemplares são referentes a vendas avulsas em bancas, o que totaliza uma circulação líquida de 459.105 unidades e um número de leitores de 1.021 .000 milhão. $^{7}$

Tendo em vista que a revista destina-se, sobretudo, a professores, e que exerce sobre sua prática certa influência, seu conteúdo e a maneira como se apresenta constituem-se, portanto, como importante foco de análise no que diz respeito às concepções e práticas de escrita desenvolvidas na escola.

\footnotetext{
${ }^{4}$ Exceto durante os meses de janeiro e fevereiro, junho e julho, quando são lançadas edições bimestrais nos dois períodos de férias escolares previstos na educação brasileira.

${ }^{5}$ Disponível em: < http://publicidade.abril.com.br/marcas/novaescola/revista/informacoes-gerais $>$ Acesso em: $1^{\circ}$ dez. 2011.

${ }^{6}$ Não incluiremos em nossa análise os anos iniciais da Educação Infantil por considerarmos que as matérias sobre escrita destinadas a essas turmas diferenciam-se daquelas dirigidas aos alunos que já dominam o código alfabético.

${ }^{7}$ Conforme o site mencionado em referência anterior, a fonte da pesquisa é atribuída à Projeção Brasil de Leitores consolidados em 2010.
}

Work. pap. linguíst., 13(2): 58-82, Florianópolis, jul.set,2012 


\section{METODOLOGIA}

Diante da proposta desta pesquisa - mapear e analisar as edições da Nova Escola que apresentam reportagens sobre produção escrita no período compreendido entre 1986 e 2010 delimitamos nosso objeto de análise às matérias que tratam do desenvolvimento desta prática, excluindo, dessa forma, aquelas que apresentam reportagens referentes à aquisição da escrita, por considerarmos que essas práticas utilizam-se de metodologias distintas ${ }^{8}$.

Nossa opção pela análise das matérias que trazem em seu conteúdo a produção textual não ignora, porém, a intrínseca relação entre esta prática, a leitura, a oralidade e a gramática. Para Antunes (2003), a escrita, assim como a fala, constitui-se como uma relação dialógica, que pressupõe um interlocutor (o leitor). A diferença, segundo a autora, é que na escrita a "recepção é adiada"'. Apesar de escrita e oralidade apresentarem especificidades, não existem, entre elas, diferenças essenciais: "Uma e outra servem à interação verbal, sob a forma de diferentes gêneros textuais, na diversidade dialetal e de registro que qualquer uso da linguagem implica" (ANTUNES, 2003, p. 99), ou seja, a relação entre escrita e oralidade não é uma relação de dependência da primeira à segunda, mas antes uma relação de interdependência (TFOUNI, 2006). A leitura constituiu-se como atividade que completa a escrita, pois é por meio dela que o leitor interpreta e reconstrói o sentido pretendido pelo autor (ANTUNES, 2003). Em relação à gramática, conteúdo de maior discrepância na visão de linguistas e gramáticos tradicionais ${ }^{10}$, Antunes afirma que, como conjunto de regras, sua finalidade é de "estabelecer os padrões de uso, de funcionamento dessa língua" (ANTUNES, 2003, p. 89, grifos da autora), o que a torna conhecida pelos falantes que a utilizam. O que eles geralmente desconhecem e a escola insiste em eleger como conteúdo primordial da disciplina de Língua Portuguesa, ressalta a autora, são as classificações e nomenclaturas dessas regras ${ }^{11}$.

\footnotetext{
${ }^{8}$ Quando tratamos do desenvolvimento da escrita por meio da produção textual, estamos nos referindo à utilização de procedimentos que concebem que o aluno já reconhece o sistema de códigos e é capaz de produzir textos a partir dele.

${ }^{9}$ Termo utilizado pela autora para distinguir a modalidade de interação verbal escrita da oral. Segundo Antunes, na escrita os sujeitos participantes da interação não ocupam o mesmo espaço ao mesmo tempo, além disso, "há um lapso de tempo, maior ou menor, entre o ato de elaboração do texto pelo autor e o ato de sua leitura pelo leitor" (ANTUNES, 2003, p. 51)

${ }^{10} \mathrm{Em}$ A constituição do discurso da mudança do ensino de língua materna do Brasil, Pietri (2003) discute o panorama de maior efervescência deste embate (década de 1980) apresentando os argumentos utilizados por linguistas e gramáticos tradicionais perante a sociedade.

${ }^{11}$ Antunes (2003) propõe o ensino das regras de uso da gramática com a finalidade de ampliar a competência comunicativa dos alunos nos processos de fala e escrita.
}

Work. pap. linguíst., 13(2): 58-82, Florianópolis, jul.set,2012 
Diante disso, nossa atenção estará voltada para as matérias de Nova Escola que se referem ao desenvolvimento da produção escrita, atentando para as mudanças referentes às sua concepções e práticas de desenvolvimento presentes nesse veículo de comunicação, contrapondo-as às instruções presentes nos documentos oficiais que regem as práticas pedagógicas de Língua Portuguesa no período analisado.

A escolha do período deu-se em função de o ano de criação da revista (1986) coincidir com o momento de discussões acerca da ineficiência observada nas práticas de ensino de língua materna até então. A década de 1990 insere-se neste trabalho por apresentar um panorama que reflete as discussões da década anterior e por ser o período de inserção de mudanças nas políticas públicas - sobretudo com a criação dos PCN do Ensino Fundamental I e II (1997; 1998); e a década de 2000, por ser considerada por nós como período capaz de refletir o panorama atual do quadro analisado ${ }^{12}$.

\section{ANÁLISE E DISCUSSÃO DOS RESULTADOS}

O levantamento das edições de Nova Escola que apresentavam matérias sobre produção de textos iniciou-se na edição 03, de abril/1986, e terminou na última edição do ano de 2010 (edição 238). Das 238 edições da revista lançadas no período compreendido nesta pesquisa tivemos acesso a 231 edições. Desse total, 44 exemplares apresentaram 46 matérias que tratavam do conteúdo de produção textual em diferentes seções ${ }^{13}$, conforme quadro 1.

\begin{tabular}{|c|c|c|c|c|}
\hline \multicolumn{2}{|c|}{ Década/Anos } & $\begin{array}{c}\text { Total de } \\
\text { exemplares } \\
\text { no período }\end{array}$ & $\begin{array}{c}\text { Número de } \\
\text { textos } \\
\text { analisados }\end{array}$ & $\begin{array}{c}\text { Não } \\
\text { tivemos } \\
\text { acesso }\end{array}$ \\
\hline 1980 & $1986-1989$ & 40 & 03 & 04 \\
\hline 1990 & $1990-1999$ & 97 & 10 & 03 \\
\hline 2000 & $2000-2010$ & 101 & 31 & 0 \\
\hline \multicolumn{2}{|c|}{ Total } & 238 & 44 & 07 \\
\hline
\end{tabular}

Quadro 1: Apresentação dos textos analisados por período.

\footnotetext{
${ }^{12}$ Ressaltamos que a divisão estabelecida é apenas para fins de organização da pesquisa, visto que estamos cientes de que as possíveis mudanças encontradas no decorrer do período analisado não compreendem delimitações temporais fixas.

${ }^{13}$ Apesar das tentativas de obter as revistas em uma biblioteca estadual e na da universidade, na década de 80 não conseguimos ter acesso às seguintes edições: 1, 2, 4, 8, todas de 1986 . Na década seguinte não encontramos três exemplares: janeiro/fevereiro de 1993, 1996 e 1997.
}

Work. pap. linguíst., 13(2): 58-82, Florianópolis, jul.set,2012 
As matérias de Nova Escola que apresentam em seu conteúdo a produção escrita encontram-se em diferentes editorias da revista e com perspectivas e objetivos distintos: reportagens explicativas, propostas didáticas, exemplos de experiências bem sucedidas de professores, etc. Por conta dessa diversidade, detivemo-nos em alguns critérios de análise buscando, dessa forma, maior aprofundamento nas questões levantadas.

Não ignoramos, nesta pesquisa, que o período analisado compreende um curto espaço de tempo em relação a mudanças significativas, porém, buscamos, por meio das reportagens analisadas, a concepção de escrita que norteia seu conteúdo e se esta se altera ao longo do período analisado. Além disso, deteremo-nos também nos gêneros que aparecem com mais frequência nas propostas didáticas presentes na revista, na metodologia utilizada e na série (turma) a que essas metodologias são destinadas, buscando analisar se há, por parte da revista, uma indicação clara dos gêneros que devem ser estudados em cada turma. Por conta da já citada relação de oposição entre a gramática tradicional e as novas propostas oriundas das ciências linguísticas, analisaremos também o peso dado à correção (gramatical) nas matérias e sua relação com o período analisado.

Juntamente com a análise desses critérios, em cada década faremos a contraposição dos dados analisados às orientações presentes nos documentos norteadores do ensino no período.

\subsection{A década de 1980}

Período significativo na história da disciplina Língua Portuguesa, por se tratar do momento considerado de mudanças nas práticas e concepções acerca da linguagem, a década de 1980 foi a que tivemos maior dificuldade de encontrar exemplares de Nova Escola que tratavam de produção escrita, e dentre aos que tivemos acesso, houve um número reduzido de matérias sobre o tema. Nessa década o tema da produção textual foi diretamente tratado apenas nas seguintes edições: abril de 1986, dezembro de 1988 e agosto de 1989. Esse baixo índice é um dado que demonstra a pouca importância ainda dada a esse conteúdo de ensino.

De maneira geral, pudemos perceber que já se mencionava nas reportagens a necessidade de mudanças na forma como a escola trabalha com as redações dos alunos. Essa premência é citada nas três reportagens, mas é explicitada, sobretudo, na reportagem de dezembro de 1988, intitulada Por que nossos alunos têm dificuldade para escrever?. A fala de uma das especialistas entrevistadas na reportagem, da Universidade Estadual de Campinas, 
é empregada para mostrar que a escola não valoriza a experiência que os alunos trazem consigo:

A escola não investiga, em nenhum momento, o que ela [a criança] sabe. Ensina gramática, tempos de verbos, pontuação, mas a atividade lingüistica é descontextualizada da experiência de vida que a criança já traz. E não lhe dá tempo de errar e corrigir, ignorando que o aluno precisaria escrever e reescrever o texto (NOVA ESCOLA, 1988, ed. 27, p. 14-15).

Outra característica também chamou nossa atenção: ao contrário das demais matérias dos anos de 1988 e 1989, que possuem no máximo quatro páginas, o texto de 88 ocupou sete páginas da revista. Esse espaço é considerado expressivo e demonstra a importância de tratar o assunto devido à recente mudança nas regras dos vestibulares, que conforme afirma a reportagem, um ano antes inseriram a redação como uma etapa eliminatória da prova. Observamos aqui novamente o grande peso que os concursos para ingresso no nível superior de ensino operam nas práticas realizadas no ensino básico, como já apontado na segunda parte deste trabalho por meio de Razzini (2000).

Outra especificidade do período, e que continuou vigorando em meados da década de 1990, é a ausência de menção aos gêneros textuais passíveis de serem trabalhados nas atividades sugeridas. Isso demonstra que o conceito ainda não estava disseminado, fato que, como veremos mais tarde, ocorre após a publicação dos PCN em 1997/1998.

Apesar do caráter inovador das matérias analisadas nessa década, observamos ainda resquícios de uma concepção de escrita que reflete a visão contestada nas discussões desse período, vinculada àquela que considerava a linguagem como instrumento de comunicação utilizado entre um emissor e um receptor e a escrita como resultado da criatividade do emissor e um dos instrumentos para a comunicação, conforme apontado na LDB de 1971. Essa concepção fica evidenciada em dois trechos da matéria de abril de 1986, intitulada Um método de redação criativa. O texto é uma entrevista pingue-pongue com o autor de um método que procura desenvolver a criatividade nas aulas de redação. O primeiro trecho afirma que é essencial que o professor leve textos de leitura que mobilizem a emoção e a imaginação do aluno e "que seja tomado não como um modelo para ser copiado, mas para, no máximo, ser reoperado". No segundo trecho, o entrevistado explica quando o aluno deve organizar sua redação: "O aluno está descontraído, com sua linguagem mobilizada e a imaginação solta". (NOVA ESCOLA, 1986, ed. 03, p. 30, grifos nossos). As expressões destacadas em negrito (reoperar e mobilizar) demonstram uma clara concepção de linguagem como mero instrumento de comunicação, visão criticada por Franchi, quando afirma: “A concepção de 
linguagem, que acreditamos estimular nossa preocupação teórica, começa por evitar reduzi-la a um papel de ferramenta social, a limitar-se pela observação de sua face exterior, puramente instrumental" (FRANCHI, 1992, p. 24). Outro destaque que fazemos no primeiro trecho citado refere-se ao conceito de criatividade que fica explícito na matéria: na fala do especialista reproduzida na revista a criatividade se limita à originalidade, imaginação e inspiração. Franchi, em um livro organizado e publicado por Possenti (2006), defende que a concepção de criatividade não pode ser reduzida ao comportamento original, à inspiração e ao desvio. Para Franchi (2006), a criatividade se manifesta quando "o falante ultrapassa os limites do codificado e manipula o próprio material da linguagem, investindo-o de significação própria” (apud POSSENTI, 2006, p. 49).

O reduzido número de matérias e o próprio teor dos textos dessa década não foram capazes de refletir o debate sobre a mudança no ensino de produção textual que se iniciava na década de 1980, momento em que se começa a pensar a linguagem em suas múltiplas realizações e como promotora da constituição dos sujeitos em um processo interativo. A discussão estava se iniciando, no entanto, essas novas ideias não tiveram ampla divulgação na revista. O fato de as matérias não refletirem o momento de mudança pelo qual a disciplina estava passando pode ser considerado como um dos fatores que contribuíram para a distância entre o que se discute teoricamente e a prática na escola.

\subsection{A década de 1990}

O período analisado é formado por dez matérias que mostram que, de maneira geral, iniciativas consideradas inovadoras na época, refletem, na verdade, a inabilidade em desvincular o ensino da Língua Portuguesa do ensino da Gramática. Nota-se um indício de mudança somente no final da década, quando há a remissão direta às propostas presentes nos PCN.

A reportagem da edição 43, de outubro de 1990, intitulada: Eles falam e falam, e vão vendo a gramática na prática, mostra uma iniciativa considerada "revigorante do ensino de Lingua Portuguesa". O texto detalha as atividades de uma professora de Língua Portuguesa de São Paulo que trabalha a gramática a partir das produções orais ou escritas dos alunos. Dentro do tema discutido os alunos vão sugerindo orações, que são transcritas no quadro e analisadas gramaticalmente em conjunto pela turma. A reportagem é totalmente permeada pelo estudo gramatical e sugere, inclusive, que o estudo linguístico se resume à 
gramática. "Há aulas em que o ponto de partida é a novela da tevê. Depois do debate, para o estudo linguístico em si. Há muitos motivos orais e escritos e de leitura que podem ser transportados para o ensino de gramática" (NOVA ESCOLA, ed. 43, p. 27), afirma a professora citada na reportagem. Observamos ainda que a profissional detém uma postura fortemente estruturalista, pois vê a língua como código, como instrumento de comunicação. Isso fica evidenciado em uma afirmação no texto da revista: “ $A$ aula de Português passa a ser uma aula de língua, de aquisição de linguagem, onde o aluno aprende a desenvolver $e$ estruturar plenamente a competência comunicativa". (NOVA ESCOLA, ed. 43, p. 28)

Essa primeira reportagem da década de 1990 sobre produção textual destaca de forma positiva uma visão que é criticada por Geraldi (1985). Para o autor, a utilização do texto como pretexto, como mero suporte para outra atividade, define o tipo de interlocução que se estabelece. Consideramos que a interlocução atingida pela atividade da professora, apesar de ser considerada inovadora, não consegue se descolar do mito até hoje vigente de que estudar Português é estudar gramática. Rojo (2008) amplia essa discussão, ao afirmar que o uso do texto como pretexto tem continuidade e está sendo suplementado pela gramaticalização do próprio texto:

Nas práticas de leitura e produção, assim como nos materiais didáticos que circulam em sala de aula, o texto entra menos como produtor de sentidos e mais como suporte de análises gramaticais, agora também textuais, como se o mero conhecimento de estruturas e tipos textuais, regras e normas pudesse fazer circular o diálogo e os sentidos. (ROJO, 2008, p. 90-91)

Podemos perceber, ainda na reportagem anterior, como a concepção do professor sobre o que é produção textual interfere na escolha das atividades. Se o professor acredita que aprender a escrever é assimilar recursos formais sintáticos ou textuais, o planejamento estará limitado a exercícios específicos sobre como unir frases, como escrever um texto a partir de algumas palavras dadas, ou seguir uma estrutura textual determinada. Mas, se esses recursos são entendidos como elementos utilizados na elaboração do discurso escrito, entendido em toda sua complexidade, o professor passa a relacionar suas atividades a situações comunicativas reais. Conforme explicitam os PCN: "Ensinar a escrever textos torna-se uma tarefa muito difícil fora do convívio com textos verdadeiros, com leitores e escritores verdadeiros e com situações de comunicação que os tornem necessários” (BRASIL, 1997, p. 28).

Na reportagem da edição 102, de maio de1997, intitulada: Cartas: aulas de escrita por correspondência houve uma tentativa de estabelecer uma situação real de interação entre os

Work. pap. linguíst., 13(2): 58-82, Florianópolis, jul.set,2012 
sujeitos, ao estimular a troca de cartas entre alunos do Ensino Fundamental e estudantes de um curso de Magistério. Apesar disso, no entanto, a professora deixou clara sua visão de produção escrita ao limitar a elaboração do texto: ela escreveu no quadro uma lista de características físicas pessoais (cor do cabelo, da pele), sugerindo que os alunos se apresentassem aos seus interlocutores.

Outro exemplo que demonstra uma concepção restrita da escrita está evidenciado na reportagem da edição 106, de outubro de1997, intitulada Versos e cores que ensinam a ler. O texto descreve uma iniciativa realizada em uma turma de segunda série: a montagem de livros de poesia que as crianças mesmo escrevem e pintam. Para a atividade, a classe escolhe um tema, em seguida a professora escreve no quadro as palavras sugeridas pelas crianças e elabora o primeiro verso do poema para estimular o início da produção.

Além da edição do ano 1990, duas outras reportagens destacam-se pelo excessivo peso dado à correção gramatical: a de outubro de 1995 e a de novembro de 1998. Na primeira, intitulada Para um bom texto, jogue as fichas, a professora cria jogos destinados a combater erros de ortografia, concordância e acentuação. Os quatro jogos apresentados na reportagem destinam-se a alunos que têm problemas de narração, que trocam letras durante a escrita, que não escrevem com sequência lógica e que têm problemas de ortografia. O segundo texto também procura explorar a questão gramatical de forma mais lúdica: intitulada Jogos em verso e prosa, a matéria apresenta a proposta de um quebra-cabeça que deve ser montado de acordo com as pistas. Suas peças são trechos de histórias. Ao ordená-las, os alunos devem recompor as narrativas e identificar classes gramaticais como verbos, adjetivos e substantivos. Essa concepção restrita de produção textual é claramente explicitada por Britto (1997), no tópico em que ele aborda a descontextualização e a falta de sentido nas atividades de leitura e produção de texto:

A prática de produção de texto, por sua vez, se relaciona com a apresentação da norma, com destaque para a correção dos erros limitados de ortografia, concordância e regência. Efetivamente, ensina-se redação apenas para fixar a norma, ainda que nem sempre se assuma esta perspectiva. (BRITTO, 1997, p. 108)

Nessa década, no entanto, encontramos em alguns textos relatos de iniciativas que consideram com menos rigidez o aspecto da correção gramatical do professor. Na matéria de setembro de 1997, intitulada Poesia: a chave da criatividade, a professora entrevistada expõe aquilo que considera preponderante na produção textual: "No primeiro momento a criatividade e a expressividade são mais importantes que a grafia. Encontrado um erro, é

Work. pap. linguíst., 13(2): 58-82, Florianópolis, jul.set,2012 
melhor perguntar à criança se deve ser mantido ou corrigido" (NOVA ESCOLA, 1997, ed. 105, p.22). Já o texto de outubro de 1999, intitulado Correção tem hora certa, descreve as atividades de uma professora que diversifica as atividades de redação e determina somente um ponto a ser trabalhado e corrigido em cada exercício. Percebemos que a correção gramatical é abordada de forma mais sutil, sugerindo que o professor deve evitar apontar várias falhas do aluno - de ortografia, concordância ou coerência - em um mesmo texto. Essas duas reportagens demonstram uma visão que já vai, de certo modo, ao encontro das propostas presentes nos PCN, que consideram que: “[...] o olhar do educador para o texto do aluno precisa deslocar-se da correção para a interpretação; do levantamento das faltas cometidas para a apreciação dos recursos que o aluno já consegue manobrar” (BRASIL, 1998, p. 77).

Os PCN defendem que a noção de gênero precisa ser tomada como objeto de ensino:

Nessa perspectiva, necessário contemplar, nas atividades de ensino, a diversidade de textos e gêneros, e não apenas em função de sua relevância social, mas também pelo fato de que textos pertencentes a diferentes gêneros são organizados de diferentes formas. (BRASIL, 1998, p. 23).

Observamos que a reportagem de 1999, mencionada no parágrafo anterior, é o primeiro registro efetivo da defesa de uma maior diversidade de textos na sala de aula. Ainda que não se utilize do termo "gênero" em nenhum momento, o último texto desta década descreve atividades da professora que usa a música, a entrevista, o poema, a fábula e a notícia para "diversificar as atividades de redação". A referida matéria é a primeira a citar textualmente as recomendações dos PCN, que haviam sido lançados havia dois anos: há um quadro em destaque que afirma que as atividades da professora estão em sintonia com o que pregam os PCN: "Poemas, fábulas e reportagens servem de modelo para os alunos, que assimilam os recursos utilizados pelos autores". (NOVA ESCOLA, 1999, ed. 126, p.20)

\subsection{A década de 2000}

Com o grande número de edições de que dispomos para a análise desse período, foinos possível perceber a crescente relevância dada ao conteúdo de produção textual na Nova Escola desde a década de 1980. Das 101 edições a que tivemos acesso na década de 2000, 31 traziam matérias sobre produção textual e, dessas, duas eram reportagens de capa da revista. A ampliação do espaço destinado à escrita na Nova Escola na década de 2000 e as discussões observadas nas matérias desse período, elegendo o trabalho com os gêneros nas atividades 
realizadas na disciplina de Língua Portuguesa, pode ser atribuída às indicações presentes nos PCN publicados na década anterior, o que demonstra que a revista procura apresentar, em suas matérias, concepções condizentes com as presentes nos documentos que representam o currículo oficial de Língua Portuguesa.

A maioria das matérias analisadas apresenta uma sugestão de trabalho baseada no conceito de gêneros textuais. Observamos que tais sugestões aproximam-se entre si e demonstram a ênfase atribuída à leitura de diferentes textos de um mesmo gênero com o intuito de conhecer melhor os aspectos que o compõem e o diferenciam de outros gêneros. Apenas em uma reportagem do início da década encontramos uma proposta didática que sugeria um primeiro contato com um único texto do gênero a ser trabalhado e a dedução pelos alunos dos aspectos composicionais do gênero "O primeiro passo foi apresentar à turma de $4^{a}$ série um modelo de carta e pedir que a garotada grifasse, em cores diferentes, a data, a mensagem, a finalização, a despedida e o remetente” (NOVA ESCOLA, ed.145, p. 37). Após a aproximação com o gênero a ser trabalhado, observamos a proposta de uma primeira produção, que nas matérias analisadas construía-se a partir de discussões entre os alunos e resultava em textos produzidos em duplas ou coletivamente. O momento da revisão do texto aparece em destaque, por ser nele que o professor aborda aspectos como a coesão textual e a gramática, preparando o aluno para a escrita da versão individual de seu texto.

A importância da revisão e da reescrita está presente em todas as matérias, sendo que algumas estão voltadas especialmente para esse aspecto, como na edição 167, de novembro de 2003, A chave para um bom texto: revisão, e na edição 226, de outubro de 2009 , Hora de aperfeiçoar. Autonomia na hora da revisão. O reconhecimento da importância dessa etapa na produção de textos se faz presente também nos PCN. Esses documentos apontam que a materialidade do texto escrito, além de promover a "recepção adiada", citada por Antunes (2003), permite o rompimento da situação de produção, fatores que permitem ao autor distanciar-se da versão inicial de seu texto para reescrevê-lo. Diante disso, os PCN (1997) sugerem que a escola incentive a prática de escritura de rascunhos para que o aluno perceba e análise o processo de construção de seu texto.

Nesse sentido, a revisão do texto assume um papel fundamental na prática de produção. É preciso ser sistematicamente ensinada, de modo que, cada vez mais, assuma sua real função: monitorar todo o processo de produção textual desde o planejamento, de tal maneira que o escritor possa coordenar eficientemente os papéis de produtor, leitor e avaliador do seu próprio texto. Isso significa deslocar a ênfase da intervenção, no produto final, para o 
processo de produção, ou seja, revisar, desde o planejamento, ao longo de todo o processo: antes, durante e depois (BRASIL, 1997, p. 46) ${ }^{14}$.

As propostas metodológicas que observamos nas matérias dessa década, apesar de destacarem a importância do trabalho com os gêneros textuais, ocorrem, na maioria das vezes, de forma instrumental, por meio de propostas didáticas e exemplos de experiências bem sucedidas de professores. Uma discussão teórica mais profunda sobre esse tema é encontrada somente na edição 224, de agosto de 2009, em que é apresentada uma explicação acerca do conceito e dos aspectos sociocomunicativos dos gêneros. Nessa matéria há também o alerta para a ineficiência de propostas metodológicas com os gêneros se estas realizarem-se na mesma perspectiva em que se trabalhava a linguagem anteriormente - descrevendo-a e conceituando-a para a memorização dos alunos. "Eles [os gêneros] invadiram a escola $-e$ isso é bom. Mas é preciso parar de ficar só ensinando suas características para passar a utilizá-los no dia a dia de todas as turmas com o objetivo de formar leitores e escritores de verdade" (NOVA ESCOLA, ed. 224, p. 48). Percebemos então que, apesar de o assunto ser abordado de forma prática desde o início da década, somente nessa matéria a revista apresenta uma explanação teórica acerca da complexidade dos gêneros como produções sociais e históricas relativamente estáveis, que não podem, portanto, ser trabalhados como conteúdos estanques na escola.

Nas propostas didáticas, é notável a insistência em determinados gêneros tradicionalmente utilizados na escola e a pouca utilização de gêneros emergentes e cada vez mais presentes no cotidiano dos alunos. Exemplo disso é a preponderância do gênero carta em comparação ao e-mail.

O gênero e-mail aparece apenas uma vez como proposta de trabalho para a produção escrita, na edição 175, de setembro de 2004. Na reportagem, Na troca de e-mails, a Língua Portuguesa ganha valor, os aspectos que compõe o gênero são explorados por meio do gênero carta, como exemplo de comunicação escrita anteriormente utilizada. Nessa reportagem, a experiência de uma professora aborda, além da finalidade comunicativa do gênero, reflexões acerca da língua e da variedade linguística.

[a professora] explorou os usos da língua portuguesa no Brasil e em Portugal por meio da troca de e-mails entres seus alunos e jovens portugueses. Assim, ampliou o conhecimento da turma sobre o texto de

\footnotetext{
${ }^{14}$ Nos PCN destinados ao terceiro e quarto ciclos do Ensino Fundamental (BRASIL, 1998) a importância da revisão do texto é apontada. Nesse documento aparece o termo "refacção" de textos, como parte do processo de escrita, procedimento que o documento sugere que deve ser ensinado na escola.
}

Work. pap. linguíst., 13(2): 58-82, Florianópolis, jul.set,2012 
cartas, agora em versão eletrônica, e aprofundou os conteúdos gramaticais em uma situação real (NOVA ESCOLA, ed. 175, p. 42).

Propostas de trabalho com o gênero carta aparecem também nas edições 145, de setembro de 2001 (Troca de cartas para escrever certo), em que os alunos são levados a reconhecer no texto as características do gênero, e na edição181, de abril de 2005, (Carta: um dos meios mais antigos de comunicação escrita), cujo objetivo é levar os alunos a reconhecerem a carta como um gênero da língua portuguesa e refletir sobre o e-mail como um desenvolvimento desse gênero mais antigo, mas a produção escrita do email não é promovida.

Acompanhando a imersão das tecnologias de comunicação e informação nos processos pedagógicos, a revista apresenta propostas que se utilizam do computador como suporte para o trabalho com os gêneros textuais por meio de atividades que propõem a conclusão de um texto, via internet, de maneira coletiva pelos alunos. Em outras matérias que abordam o uso do computador, este é apontado como ferramenta que auxilia na prática de produção de textos. Nessas matérias, observamos que o uso do computador é destinado ao momento de revisão das produções,

Em processadores como o Word, a verificação ortográfica é muito facilitada. [...] Em termos de organização textual, a vantagem é poder mudar de lugar, ampliar, cortar e eliminar frases e parágrafos, experimentando novas soluções para a composição sem precisar escrever tudo de novo a cada nova versão (NOVA ESCOLA, ed. 223, p. 52).

Também a matéria De olho na tela destaca a utilização do computador nesse sentido, "Na hora de revisar, o computador é o melhor instrumento para a turma explorar várias maneiras de aperfeiçoar um texto sem perder tempo" (NOVA ESCOLA, ed. 227, p. 70). Nessas matérias, o uso do computador é apresentado focalizando a correção ortográfica e a formatação, o que restringe a utilização dessa ferramenta às ações de melhoria do texto. Nessa perspectiva, ignora-se que, ao utilizar-se do computador, o aluno depara-se com uma situação de comunicação em que são produzidos gêneros específicos que poderiam ser também trabalhados. Ao não explorar esses gêneros, a revista demonstra que ainda subutiliza essa ferramenta nas práticas com a escrita.

No ano de 2009, observamos que as matérias buscam demonstrar ao professor um novo enfoque na produção de textos, apresentando conhecimentos teóricos e metodológicos como meio de possibilitar mudanças nos alunos em relação a sua escrita. A edição 219, de 
janeiro e fevereiro de 2009, traz na capa a reportagem Produção de texto: escrever de verdade abordando a importância de os alunos terem conhecimento da situação de produção na hora de escrever seu texto "Para produzir textos de qualidade, seus alunos têm de saber o que querem dizer, para quem escrevem e qual é o gênero que melhor exprime essas ideias" (NOVA ESCOLA, ed. 219, p. 39). Também a edição 222, de maio de 2009 (O que e para $q u e(m$,), aborda a importância de projetos didáticos que deixem claro para o aluno a situação de produção e a finalidade do seu texto, "uma boa proposta de texto precisa ter propósitos claros. Trata-se [...] de garantir as chamadas condições didáticas da escrita: o que escrever? Para que escrever? E, finalmente, para quem escrever? Somente respondendo a essas perguntas é possível determinar como escrever" (NOVA ESCOLA, ed. 222, p. 78).

Nos PCN essa indicação é clara no que diz respeito à prática de produção de textos,

Compreendida como um complexo processo comunicativo e cognitivo, como atividade discursiva, a prática de produção de textos precisa realizar-se num espaço em que sejam consideradas as funções e o funcionamento da escrita, bem como as condições nas quais é produzida: para que, para quem, onde e como se escreve (BRASIL, 1997, p. 44).

A matéria $O$ que e para que $(m)$ apresenta ainda uma crítica às tradicionais redações de "tema livre" que, além de desconsiderar as condições nas quais a escrita é produzida, apoiavam-se em uma concepção de linguagem como expressão do pensamento, considerando que para escrever bastava ao aluno inspiração. "Textos de tema livre costumam desconsiderar esses requisitos básicos [condições de produção dos textos]. O resultado, quase sempre, é desastroso" (NOVA ESCOLA, ed. 222, p. 78). Essa matéria apresenta ainda a importância da leitura para o conhecimento de diferentes gêneros e da revisão na construção de um bom texto.

A importância da leitura é ressaltada também na matéria da edição 221 , de abril de 2009 (Ler para escrever), que demonstra a importância dessa prática para o desenvolvimento da escrita, apontando a leitura voltada para a produção de textos "exige intenção e um encadeamento bem definido de atividades, que tenham como principal objetivo mostrar como redigir textos específicos" (NOVA ESCOLA, ed. 221, p. 54). A indicação presente nessa matéria é que os alunos/leitores devem buscar nos textos que leem aspectos como as intenções comunicativas e os estilos dos autores, no intuito de ajudá-los a resolver seus problemas de escrita. A prática da leitura na melhoria da produção de textos já havia sido mencionada na edição 205, de setembro de 2007, A turma sabe ler e escrever. E agora? porém, com destaque para a reflexão dos aspectos gramaticais do texto. Nessa matéria, segundo a professora

Work. pap. linguíst., 13(2): 58-82, Florianópolis, jul.set,2012 
entrevistada, "O professor tem de introduzir questões ortográficas e de pontuação ao mostrar à turma a necessidade de buscar uma leitura fluente e agradável” (NOVA ESCOLA, ed. 205, p. 44).

Da correlação estabelecida entre os gêneros propostos para atividades em sala de aula e a série a que estas atividades se destinam, observamos que os gêneros com sequências textuais narrativas são geralmente mais voltados aos alunos que estão iniciando a produção escrita - séries iniciais e primeiro ciclo do Ensino Fundamental - enquanto os gêneros com sequências textuais argumentativas e descritivas, como o texto publicitário, o artigo de opinião, a resenha literária e a peça de teatro são destinados às turmas de $5^{\mathrm{a}}$ a $8^{\mathrm{a}}$ série. As turmas do Ensino Médio são citadas apenas em uma proposta com o gênero poesia. $\mathrm{O}$ excessivo número de matérias sobre produção de textos para o Ensino Fundamental em relação ao Ensino Médio demonstra o pouco espaço destinado na revista à prática de produção textual voltada para os alunos que se encontram no final do percurso escolar.

Em relação à correção gramatical, a importância de uma correta grafia e pontuação para melhor coerência do texto é recorrente em todas as matérias, porém, observamos a preponderância dada ao aspecto discursivo do texto, ao que o aluno tem a dizer. As matérias apresentam as atividades de análise linguística a partir dos textos dos alunos, sobretudo nas atividades de revisão e reescritura. Percebemos que as atividades relacionadas aos conteúdos como ortografia e gramática são considerados importantes, mas não apontadas como única maneira de o aluno desenvolver habilidades com a leitura e a escrita.

Eles continuam sendo muito importantes [...], pois conhecê-los é essencial para que os alunos superem as dificuldades. Que tempo verbal usar para contar algo que já aconteceu? Que recursos de coesão e coerência garantem a compreensão de uma história? [...] Para alcançar isso, porém, não é necessário colocar a ortografia e a gramática como 'um fim em si mesmo', ocupando o centro das aulas. Assim como os gêneros, elas são um meio para ensinar a ler e escrever cada vez melhor (NOVA ESCOLA, ed. 224 , p. 50,52).

A diversidade de metodologias de ensino da escrita também é foco de divulgação da revista. Na edição 224, de agosto de 2009, é destacada a importância de mesclar as modalidades de projeto didático e de sequência didática visando sempre à progressão das dificuldades. Na matéria dessa edição, Como trabalhar com gêneros, observamos que a revista aponta o projeto como a modalidade mais indicada para trabalhar com a escrita, já que os alunos sabem que escrevem para um público que vai além do professor, e, por isso, "capricham" mais na tentativa de se fazer entender, enquanto que a sequência é mais

Work. pap. linguíst., 13(2): 58-82, Florianópolis, jul.set,2012 
apropriada para trabalhar com atividades de leitura, pois permite o planejamento de uma sequência de leituras de vários textos de um mesmo gênero. Diante disso, observamos a discrepância entre as indicações da revista e a metodologia da Sequência Didática desenvolvida em Genebra, já que esta é pensada para a produção de gêneros orais e escritos e admite, em ambas, as situações de produção, a prática da leitura.

Apesar de apresentar, em matéria do início da década, confusão acerca do conceito de gêneros e tipos textuais ${ }^{15}$; percebemos, por meio das reportagens e propostas de atividades no decorrer dos anos, que este conceito está bem difundido ${ }^{16}$ e pode ser considerado, pelo modo como é tratado na revista, como conceito subentendido pelos leitores. A intersecção do uso das tecnologias com a produção escrita é explorada na medida em que serve ao gênero trabalhado ou às atividades de revisão do texto. Não observamos nenhuma proposta que articulasse o uso do computador a um gênero específico de sua esfera. Porém, as mudanças são notáveis em relação às décadas anteriores. A importância destinada à leitura, às condições nas quais o texto é produzido, à compreensão da posição do aluno como autor de seu texto está presente nas matérias analisadas, que chamam a atenção para esses fatores, alertando os professores da ineficiência de práticas que não provocam no aluno o desejo de produzir um texto.

\section{CONSIDERAÇÕES FINAIS}

A partir da seleção dos 46 textos da Nova Escola foi possível vislumbrarmos as mudanças referentes às concepções e práticas da escrita entre os anos de 1986 e 2010 . A análise das matérias que contemplaram o foco da pesquisa, além das concepções de escrita presentes nos documentos norteadores do ensino no período, nos permitem afirmar que

\footnotetext{
${ }^{15}$ Em uma matéria destinada à importância da revisão em um texto, uma proposta didática sugerida pela revista trazia "Ao solicitar que a turma faça uma redação, defina o tema, o gênero textual (narrativo, opinativo, informativo etc.), quem será o leitor e qual a finalidade do trabalho"( NOVA ESCOLA, ed.167, p. 31, grifos nossos).

${ }^{16}$ É importante ressaltar a diferença entre as noções de gênero textual e tipo textual. Os gêneros textuais são os textos que encontramos em nossa vida diária, em situações comunicativas e que, segundo Marcuschi (2008), apresentam padrões sociocomunicativos característicos, definidos por composição funcionais, objetivos enunciativos e estilos concretamente realizados na integração de forças históricas, sociais, institucionais e técnicas. Como os gêneros textuais são respaldados nas práticas sociais, na dinâmica da vida social e cultural, eles podem sofrer variações em suas unidades temáticas, forma composicional e estilo, ou seja, são tipos relativamente estáveis de enunciados (BAKHTIN, 2003). Os tipos textuais caracterizam-se como sequências linguísticas, definidas pela sua composição (aspectos lexicais, sintáticos, tempos verbais, relações lógicas, estilo). Em geral, constituem os tipos textuais a narração, a argumentação, a exposição, a descrição e a injunção. (MARCUSCHI, 2008, p. 154).
} 
houve, por parte da revista, um movimento de apropriação das práticas de linguagem mais discutidas em cada período. Além disso, por meio do breve resgate histórico empreendido, é possível observarmos que, no ambiente escolar, o papel da escrita esteve muitas vezes condicionado às exigências sociais externas à escola, sem, contudo, considerar esses contextos nas práticas de produção de texto desenvolvidas.

Apesar de o momento de maior efervescência das discussões acerca das práticas de ensino e produção de textos ter sido na década de 1980, seus reflexos na revista aparecem somente a partir da década de 1990, tendo, nos anos 2000, maior destaque. Atribuímos esse movimento à consolidação das propostas sugeridas pelos PCN no ensino público brasileiro no final da década de 1990 e também à disseminação do conceito de gênero proposto por Bakhtin (2003). Dessa forma, percebemos que o veículo, ainda que não simultaneamente, acompanhou as mudanças demandadas pela prática da disciplina de Língua Portuguesa e, ao longo dos anos, sua visão de produção textual é claramente modificada: o foco sai da redação (anos 1980) para um intenso trabalho com os gêneros textuais (anos 2000). 


\section{REFERÊNCIAS}

ANTUNES, Irandé. Aula de Português: encontro \& interação. São Paulo: Parábola Editorial, 2003.

BAKHTIN, Mikhail. Os gêneros do discurso. In: Estética da criação verbal. São Paulo: Martins Fontes, 2003 - p. 261-306.

BRASIL. MEC. Parâmetros Curriculares Nacionais: Língua Portuguesa ( $1^{\mathrm{a}}$ a $4^{\mathrm{a}}$ séries). Brasília: MEC/SEF, 1997.

. Parâmetros Curriculares Nacionais: Língua Portuguesa ( $5^{\mathrm{a}}$ a $8^{\mathrm{a}}$ séries). Brasília: MEC/SEF, 1998.

Lei $n^{\circ} 5.692$, de 11 de agosto de 1971. Fixa diretrizes e bases para o ensino de $1^{\circ}$ e $2^{\circ}$ graus, e dá outras providências. Brasília: Congresso Nacional, 1971.

BRITTO, Percival Leme. A sombra do caos: ensino de línguas x tradição gramatical. Campinas: Mercado de Letras, 1997.

FORTUNATO, Márcia Vescovi. Autoria e aprendizagem da escrita. Tese (Doutorado em educação) - Universidade de São Paulo, USP, 2009.

FRANCHI, Carlos. Linguagem - atividade constitutiva. Cadernos de Estudos Lingüisticos, n. 22. Campinas: IEL, jan./jun. 1992. p. 9-39. (publicado originalmente em Almanaque, n. 5, São Paulo: Brasiliense, p. 9-26, 1977.

GERALDI, Wandeley (org.). O texto na sala de aula. $3^{\text {a }}$. Ed. Cascavel - Paraná: Assoeste, 1985. . Portos de Passagem. São Paulo: Martins Fontes, 1997.

KLEIMAN, Ângela B. Os significados do letramento: uma nova perspectiva sobre a prática social da escrita. Campinas: Mercado de Letras, 1995.

MARCUSCHI, Beth. Escrevendo na escola para a vida. In: Rangel. E. O. e Rojo, R. H. (orgs.) Coleção Explorando o ensino - Língua Portuguesa, Brasília, MEC, Secretaria de Educação Básica, 2010 - p. 65-84.

MARCUSCHI, Luiz Antônio. Produção textual, análise de gêneros e compreensão. São Paulo : Parábola Editorial, 2008.

PETRONI, Maria Rosa. Gêneros do discurso, leitura e escrita: experiências de sala de aula. In: PETRONI, Maria Rosa (Org.). Gêneros do discurso, leitura e escrita: experiências de sala de aula. São Carlos: Pedro \& João Editores / Cuiabá: EdUFMT, 2008 - p. 9-16. 
PIETRI, Emerson de. A constituição do discurso da mudança do ensino de língua materna no Brasil. Tese (Doutorado em Linguística Aplicada) - Instituto de Estudos da Linguagem, UNICAMP, 2003.

POSSENTI, Sírio. (org.). Mas o que é mesmo "gramática”? São Paulo: Parábola, 2006.

RAZZINI, Marcia de Paula Gregório. O espelho da nação: a Antologia Nacional e o ensino de português e de literatura (1838-1971). Tese (Doutorado em Teoria Literária) - Instituto de Estudos da Linguagem, UNICAMP, 2000.

RODRIGUES, Rosângela Hammes. Os gêneros do discurso na perspectiva dialógica da linguagem: a abordagem de Bakhtin. In: MEURER, José Luiz; BONINI, Adair; MOTTAROTH, Désirée Org(s). Gêneros: teorias, métodos, debates. São Paulo: Parábola Editorial, 2005, p. 152-183.

ROJO. R. Gêneros de discurso/texto como objeto de ensino de línguas: um retorno ao trivium? In: SIGNORINI, Inês. (Org.) [Re]discutir texto, gênero e discurso. São Paulo: Parábola, 2008. p. 73-103.

SCHELBAUER, Analete Regina. Entre anúncios e artigos. In: SCHELBAUER, Analete Regina, ARAÚJO, José Carlos Souza, (Orgs.). História da educação pela imprensa. Campinas, SP: Editoria Alínea, 2007.

SCHNEUWLY, Bernard; DOLZ, Joaquim. Gêneros orais e escritos na escola. Trad. e Org. Roxane Rojo e Glaís Sales Cordeiro. Campinas, SP: Mercado de Letras, 2004.

SOARES, Magda. Português na escola: História de uma disciplina curricular. In: BAGNO, Marcos (Org.). Linguística da norma. São Paulo: Loyola, 2002. p. 155-177.

SOUZA, Paulo Nathanael Pereira de; SILVA, Eurides Brito. Como entender e aplicar a nova LDB. São Paulo: Pioneira, 1997.

TFOUNI, Leda Verdiani. Letramento e Alfbetização. 8. ed. São Paulo: Cortez, 2006. 